\title{
Cannabidiol Attenuates Methamphetamine-Induced Cardiac Inflammatory Response and Necrosis through The PKA/CREB Signaling Pathway
}

\section{Qianyun Nie}

Kunming Medical University

\section{Wenjuan Dong}

Kunming Medical University

\section{Baoyu Shen}

Kunming Medical University

Genmeng Yang

Kunming Medical University

\section{Hao Yu}

Kunming Medical University

\section{Ruilin Zhang}

Kunming Medical University

\section{Yanxia Peng}

Kunming Medical University

\section{Yang Yu}

Kunming Medical University

Shijun Hong ( $\nabla$ hongshijun@kmmu.edu.cn )

Kunming Medical University

\section{Lihua Li}

Kunming Medical University

\section{Research Article}

Keywords: cannabidiol, methamphetamine, cardiotoxicity, inflammatory response, protein kinase A, cyclic adenosine monophosphate response element-binding

Posted Date: December 20th, 2021

DOI: https://doi.org/10.21203/rs.3.rs-1159875/v1

License: (c) (1) This work is licensed under a Creative Commons Attribution 4.0 International License.

Read Full License 


\section{Abstract}

Methamphetamine (MA) abuse is a major global public health problem, with cardiovascular issues becoming an increasingly recognized complication. Cannabidiol (CBD) has gained recent attention, due to its various pharmacological properties. However, whether CBD has therapeutic effects on MA-induced cardiotoxicity remains unknown. In the present study, we investigated whether CBD has a protective or therapeutic effect on MA-induced cardiac damage in rats via the protein kinase $A$ (PKA)/cyclic adenosine monophosphate response element-binding (CREB) signaling pathway. Thirty rats were randomly divided into five groups. The rats were administered MA by intraperitoneal injection (IP) once a day for 4 weeks, with CBD (40 or $80 \mathrm{mg} / \mathrm{kg}, \mathrm{IP}$ ) treatment $1 \mathrm{~h}$ prior to the MA injections. Body and heart weights were measured, and morphological changes were determined using hematoxylin \& eosin and Masson's trichrome staining. The serum levels of interleukin-6 (IL-6) and IL-10 were detected using enzyme linked immunosorbent assay (ELISA) kits. The protein expression levels of PKA, phospho-PKA (p-PKA), CREB, phospho-CREB ( $p$-CREB) and cardiac troponin I (cTnl) in the myocardium were detected by western blot analysis. Results showed that the heart-to-body weight ratio increased significantly following MA administration but decreased with CBD treatment. Chronic administration of MA resulted in a cardiac inflammatory response and progressive development of fibrosis, while CBD treatment attenuated these lesions in a dose-dependent manner. MA administration increased IL- 6 but decreased IL-10 levels, which were reversed by CBD pretreatment. Moreover, MA significantly increased the cTnl level, but this was decreased by CBD treatment at $80 \mathrm{mg} / \mathrm{kg}$. The protein expression levels of PKA, p-PKA, CREB, and p-CREB increased following MA administration, but significantly decreased with CBD treatment. Overall, these results indicate that chronic MA administration leads to cardiotoxicity, including cardiac inflammatory response, fibrosis, and myocardial necrosis, but these effects can be attenuated by CBD pretreatment. Our research suggests a potential application of CBD for MA-induced cardiotoxicity, which may attenuate inflammatory response and necrosis through the PKA/CREB signaling pathway.

\section{Introduction}

Methamphetamine (MA) is a highly addictive class of synthetic stimulant and one of the most popular drugs of abuse worldwide(World Drug Report 2020). The number of young MA users has increased dramatically in recent years, resulting in criminal detention and medical resource shortages. Thus, MA abuse has become of increasing concern and is a major global public health problem(Kohno et al., 2020, Spivak et al., 2020). The molecular structure of MA consists of a methyl group added to the base structure of amphetamine (Fig. 1A). MA is highly lipophilic, allowing it to readily cross the blood-brain barrier(Homer et al., 2008), where it can affect the central nervous system by increasing catecholamine (e.g., dopamine and norepinephrine) expression via multiple mechanisms(Sulzer et al., 2005, Krasnova and Cadet, 2009, Reiner et al., 2009, Shaerzadeh et al., 2018). Many studies have focused on the neurotoxic effects, neuropsychiatric deficits, and addiction profiles of MA(Moratalla et al., 2017, DerGhazarian et al., 2019, Pan et al., 2020, Razavi et al., 2020). However, MA is a sympathomimetic amine substance, and can have a series of sides effects on multiple organs, such as the brain, heart, kidney, and 
spleen, following overdose and chronic administration(Rusyniak, 2011, Gurel, 2016, Wu et al., 2016, Isoardi et al., 2020). Of note, cardiovascular injury caused by MA use has gained recent attention.

Hypertensive heart disease, pulmonary hypertension, delayed cardiomyopathy, and cardiogenic shock are frequently found in MA abusers, with sudden unexpected death also reported(Nishida et al., 2003, Segawa et al., 2019, Dalal et al., 2020, Hendrickson and Strauss, 2020). A retrospective study on autopsy found that cardiovascular disease is the second leading cause of death in MA abusers, after accidental drug toxicity(Darke et al., 2017). Furthermore, $68 \%$ of MA poisoning-related deaths are reported to show changes in cardiovascular pathology(Akhgari et al., 2017). Cardiovascular complications from MA are increasingly recognized and include vasoconstriction, hypertension, arrhythmia, aortic dissection, acute coronary syndromes, pulmonary arterial hypertension, atherosclerotic coronary artery disease, cardiomyopathy, and heart failure(Paratz et al., 2016, Kevil et al., 2019, Nishimura et al., 2019). The molecular mechanisms underlying MA-associated cardiovascular injury are likely multifactorial, intracellular calcium and potassium homeostasis defects, reactive oxygen species (ROS) generation, oxidative stress, mitochondrial dysfunction, and apoptosis may be related to direct damage(Liang et al., 2010, Lord et al., 2010, Reddy et al., 2020). MA can exert toxic effects indirectly via catecholamines due to its high affinity with dopamine and norepinephrine transporters(Han and $\mathrm{Gu}, 2006)$. Moreover, trace amino acid receptor 1 and sigma-1 receptor also play important roles via interactions with MA in the cardiovascular system(Nguyen et al., 2005, Lewin et al., 2011). High catecholamine levels can lead to vasospasm, hypertension, tachycardia, and myocardial ischemia(Won et al., 2013). Through the above pathophysiological mechanisms, MA eventually causes cardiac systolic dysfunction and inflammation, progressing to fibrosis and cardiomyopathy(Reddy et al., 2020).

Inflammation is an important risk factor for cardiovascular disease(Sethwala et al., 2021), and also plays a key role in MA-induced cardiac injury. Endomyocardial biopsies from the left ventricles of patients with MA-associated cardiomyopathy show increases in myocyte damage and markers of inflammation and fibrosis(Schurer et al., 2017). Myocarditis and endocarditis are also found in MA abusers during postmortem examination(Darke et al., 2017). The pathological development of cardiac inflammation can lead to arteriosclerosis, coronary heart disease, heart structure remodeling, and dilated cardiomyopathy(Gao et al., 2015, Kevil et al., 2019, Reddy et al., 2020). However, the molecular mechanism of myocardial inflammation induced by MA exposure has not yet been fully elucidated. Reducing mitochondrial membrane potential and promoting ROS expression induced by MA may potentiate the inflammatory process(Potula et al., 2010). Toll-like receptor 4 (TLR4) plays an important role in immune and inflammatory responses by activating nuclear factor kappa-light-chain-enhancer of activated B cells (NF-KB), which further regulates the expression of cytokines. The TLR4/NF-KB signaling pathway is involved in the pathology of MA-induced inflammation in BV2 cells, increasing the level of proinflammatory cytokines such as tumor necrosis factor-a (TNF-a), interleukin-6 (IL-6), and interleukin-1 $\beta$ (IL-1ß)(Wan et al., 2017). The cyclic adenosine monophosphate (cAMP)/protein kinase A (PKA)/cAMP response element-binding (CREB) signal transduction pathway is involved in a variety of physiological and pathological processes, which can modulate working memory, cognitive function, fibrosis, and inflammation(Vandesquille et al., 2013, Li et al., 2015, Wang et al., 2015, Tanaka et al., 2020). However, 
whether the cAMP/PKA/CREB signaling pathway is involved in MA-induced myocardial inflammation remains poorly understood.

Although autopsy, clinical, and animal studies provide compelling evidence of cardiovascular dysfunction, the Food and Drug Administration has not approved any specific treatments or drugs for cardiac complications caused by MA. Cannabidiol (CBD) (Fig. 1B) is a non-psychoactive component of Cannabis sativa(Mechoulam and Hanus, 2002), which is considered safe and well tolerated in high doses and chronic use(Bergamaschi et al., 2011, Shayesteh et al., 2019). In recent years, CBD has been applied in the treatment of various diseases, such as epilepsy, schizophrenia, addiction, anxiety, and neonatal ischemic encephalopathy(Devinsky et al., 2014, Sands et al., 2019), and shows multiple effects, including immunosuppression, anti-inflammation, anti-fibrosis, neuroprotection, and anti-oxidation activity(GarciaArencibia et al., 2007, Campos et al., 2017, Nichols and Kaplan, 2020, Sunda and Arowolo, 2020). Furthermore, CBD shows therapeutic effects on MA-induced reward and protective effects on impairment of recognition memory(Razavi et al., 2020, Yang et al., 2020a). However, whether CBD has a therapeutic effect on MA-induced cardiac inflammation remains unclear.

In the present study, we explored the potential protective effects of CBD and involvement of the PKA/CREB signaling pathway in MA-induced cardiac inflammation. We evaluated the therapeutic effects of CBD on cardiac inflammation induced by MA and the expression of key factors of the PKA/CREB signal pathway in the myocardium of rats, which may provide a novel strategy for the treatment of cardiotoxicity induced by MA abuse.

\section{Materials And Methods}

\section{Reagents and chemicals}

We legally obtained MA (purity above 98\%) from the Yunnan Provincial Public Security Department. The MA was dissolved in saline and administered at a dose of $10 \mathrm{mg} / \mathrm{kg}$ via intraperitoneal injection (IP). The dose of MA was based on previous studies, with slight adjustment(Friend et al., 2013, Meng et al., 2020). The CBD was purchased from Hebei Fan Zhang Tang Commercial and Animal Husbandry Co., Ltd. (Cat. \#: 13956-29-1, Hebei, China). It was dissolved in a vehicle solution of $5 \%$ dimethyl sulfoxide (DMSO) and $5 \%$ polysorbate 80 (Tween-80) in saline and then IP administered at doses of 40 and $80 \mathrm{mg} / \mathrm{kg}$. The CBD dosages were selected according to the results of our previous study(Yang et al., 2020a). Tween-80 was purchased from Beijing Solarbio Science \& Technology Co., Ltd. (Cat. \#: T8360, Beijing, China), and DMSO was purchased from Sigma-Aldrich (St. Louis, MO, USA).

\section{Animals and experimental design}

Thirty male Sprague-Dawley rats ( 6 weeks old, 180-220 g) were purchased from the Laboratory Animal Center of Kunming Medical University (KMU). All animal studies were performed in accordance with the Guidelines for the Care and Use of Laboratory Animals of KMU, and all experimental procedures were approved by the Ethics Committee on Animal Care and Use from KMU (Approval code: kmmu2020403). 
Rats were housed together ( 6 rats/cage) and provided with free access to food and water under standard conditions (room temperature of $22 \pm 1{ }^{\circ} \mathrm{C}$, humidity of $50 \%-60 \%$, and 12-h:12-h light: dark cycle). All rats were acclimatized to the new environment for 3 days prior to the start of the experiments. The rats were randomly divided into five experimental groups ( $n=6 /$ group): i.e., solvent control group (saline solution containing 5\% DMSO + 5\% Tween-80, $10 \mathrm{ml} / \mathrm{kg}, \mathrm{IP}$ ), $\mathrm{CBD}_{80}$ group (CBD, $80 \mathrm{mg} / \mathrm{kg}, \mathrm{IP}$ ), MA group (MA, 10 $\mathrm{mg} / \mathrm{kg}, \mathrm{IP}), \mathrm{CBD}_{40}(40 \mathrm{mg} / \mathrm{kg})+\mathrm{MA}$ group, and $\mathrm{CBD}_{80}(80 \mathrm{mg} / \mathrm{kg})+\mathrm{MA}$ group. The rats received MA or CBD once a day (at 09:00 am) for 4 weeks, with the MA $(10 \mathrm{mg} / \mathrm{kg})$ injections given $1 \mathrm{~h}$ after CBD treatment (40 or $80 \mathrm{mg} / \mathrm{kg}, \mathrm{IP}$ ), and weighed weekly for dose adjustment. All rats were sacrificed by narcotic overdose $24 \mathrm{~h}$ after the last injection. Cardiac blood (for serum) and hearts were collected. Some hearts were fixed in $4 \%$ paraformaldehyde solution, and some hearts were stored at $-80^{\circ} \mathrm{C}$ until further analysis. The experimental protocols are shown in Fig. 1C.

\section{Histopathological examination}

The hearts were fixed in 4\% paraformaldehyde solution, dehydrated, embedded in paraffin wax, and sliced into $5-\mu \mathrm{m}$ thick sections using a microtome (RM2235, Leica, Germany). The sections were then stained with hematoxylin \& eosin (H\&E) to assess inflammatory and necrotic changes in tissue and with Masson's trichrome to assess fibrotic changes. The heart tissue sections were examined using a digital pathological section scanning system (KF-PRO-005-EX, KFBIO, Ningbo, China)(Song et al., 2020).

\section{Enzyme linked immunosorbent assay (ELISA)}

The cardiac blood serum levels of pro-inflammatory cytokine IL- 6 and anti-inflammatory cytokine IL-10 were measured using rat ELISA kits (Mlbio, Shanghai, China) in accordance with the manufacturer's protocols. Absorbance was recorded at $450 \mathrm{~nm}$.

\section{Western blot analysis}

The left ventricles of the hearts were dissected and lysed in enhanced radioimmunoprecipitation assay (RIPA) lysis buffer (Beyotime, Shanghai, China) containing 1\% protease inhibitor and $1 \%$ phosphatase inhibitor on ice for $30 \mathrm{~min}$, then centrifuged at $12000 \mathrm{rpm}$ for $15 \mathrm{~min}$ at $4{ }^{\circ} \mathrm{C}$. Protein concentrations were measured using an enhanced bicinchoninic acid (BCA) protein assay kit (Beyotime, Shanghai, China). Equal amounts of protein $(50 \mu \mathrm{g})$ were separated via $12 \%$ sodium dodecyl sulfate-polyacrylamide gel electrophoresis (SDS-PAGE) and transferred with a constant current onto $0.45-\mu \mathrm{m}$ polyvinylidene fluoride (PVDF) membranes (Millipore, MA, USA). The membranes were sealed with non-fat dry milk (diluted in TBST buffer) for $2 \mathrm{~h}$ at room temperature, then incubated overnight at $4{ }^{\circ} \mathrm{C}$ with primary antibodies: rabbit anti-PKA (Proteintech, IL, USA, 1:1000), rabbit anti-p-PKA (Abcam, Cambridge, UK, 1:1000), rabbit anti-CREB (Proteintech, IL, USA, 1:1 000), rabbit anti-p-CREB (CST, Massachusetts, USA, 1:1 000), rabbit anti-cardiac troponin I (cTnI) (Proteintech, IL, USA, 1:2000), and rabbit anti-GAPDH (Servicebio, Wuhan, China, 1:2000). The membranes were washed with TBST three times, incubated with horseradish peroxidase (HRP)-linked anti-rabbit IgG secondary antibody (Abbkine, Wuhan, China, 1:5000) for $1.5 \mathrm{~h}$ at room temperature, then washed again (as above). The membranes were detected using an ultra-high 
sensitivity electrochemiluminescence kit (Biosharp, Beijing, China) and images were captured by the BioRad imaging system (Bio-Rad, Hercules, California, USA). Protein bands were determined by Image $\mathrm{J}$ software and the intensities of each band were normalized to GAPDH. The experiment was repeated in triplicate and representative western blot images were presented.

\section{Statistical analysis}

All data are expressed as mean \pm standard deviation (SD). Statistical analyses were performed with SPSS v21.0 (IBM SPSS, Chicago, USA), and graphs were constructed using GraphPad Prism v6.0 (GraphPad Software, USA). One-way analysis of variance (ANOVA) was used to analyze experimental data, followed by Tukey's post-hoc tests for comparing individual groups. Paired $t$-test was applied to evaluate body weight between pre- and post-drug administration. Significance was defined at $P<0.05$.

\section{Results}

\section{Effects of CBD on MA-induced body and heart weight changes in rats}

Body weight was measured before drug injection and at 1 to 4 weeks after drug administration. Body weight showed a time-dependent increase and was significantly higher after 4 weeks of administration than before administration in each group $(P<0.01$, Fig. $2 A)$. Weight gain was lower in the MA group than in the control group but showed no significant difference between the two groups after 4 weeks of administration. Compared with the MA group, CBD had no effect on body weight at either dose (40 or 80 $\mathrm{mg} / \mathrm{kg}$ ) (Fig. 2A). The hearts were weighed immediately after dissection. As shown in Fig. 2B, although heart weight increased slightly in the MA group compared to the control group, this increase was not statistically significant. Interestingly, however, 1 -h pretreatment with $80 \mathrm{mg} / \mathrm{kg}$ of CBD reduced MAinduced cardiomegaly compared to the MA group $(P<0.01)$. The heart-to-body weight ratio increased significantly in the MA group compared to the control group $(P<0.01$, Fig. $2 C)$, whereas CBD $(80 \mathrm{mg} / \mathrm{kg})$ pretreatment for $1 \mathrm{~h}$ reduced the ratio compared to the MA group $(P<0.01$, Fig. $2 \mathrm{C})$. These results suggest that chronic exposure to MA for 4 weeks can induce cardiomegaly in rats, to some extent, which can be inhibited by administration of CBD $(80 \mathrm{mg} / \mathrm{kg})$.

\section{CBD attenuates MA-induced cardiac inflammatory response}

The H\&E-stained heart tissues in the MA group showed myocardial fiber disorder, mild interstitial oedema, mild myocyte hypertrophy, vacuolization and karyolysis, as well as distinct mononuclear inflammatory infiltration in interstitial spaces or around blood vessels, and focal lesions with necrosis. As shown in Fig. 3C, focal mononuclear inflammatory infiltration was observed with myocardial necrosis and fibrosis. The myocardial structure of the control and $\mathrm{CBD}_{80}$ groups was mostly normal (Fig. $3 \mathrm{~A}$ and $3 \mathrm{~B}$ ). However, pretreatment with 40 or $80 \mathrm{mg} / \mathrm{kg}$ CBD for $1 \mathrm{~h}$ before MA administration resulted in gradual and effective suppression of cardiac lesions. As shown in Fig. 3D and 3E, only slight mononuclear inflammatory infiltration in the interstitial spaces or around blood vessels was observed, mainly manifested as myocardial cell degeneration. Myocardial fibrosis is a progressive pathological process of chronic 
inflammation. Here, Masson's trichrome staining was used to evaluate fibrosis in the myocardium, resulting in blue-brown-stained nuclei, red-stained cytoplasm and myofiber, and blue-stained collagen fibers. As shown in Fig. 3H, more blue-stained collagen fibrils in the perivascular and interstitial spaces were observed in the MA group than in the control group. Compared with the MA group, $40 \mathrm{mg} / \mathrm{kg}$ CBD pretreatment reduced the extent of fibrosis, although perivascular fibrosis remained (Fig. 3I), whereas there was almost no fibrosis in the $80 \mathrm{mg} / \mathrm{kg}$ CBD group (Fig. 3J). To further assess MA-induced inflammation and effects of CBD on inflammation, we evaluated the cardiac blood serum levels of proinflammatory cytokine IL- 6 and anti-inflammatory cytokine IL-10 via ELISA. As shown in Fig. 4A, the level of IL- 6 increased significantly in the MA group compared to that in the control group. However, IL-6 expression decreased dose-dependently following CBD pretreatment. In addition, MA significantly reduced the expression of IL-10 compared to that in the control group, whereas CBD pretreatment increased the level of IL-10 in a dose-dependent manner (Fig. 4B). Thus, chronic administration of MA in rats can cause a cardiac inflammatory response and progressive development of fibrosis, while CBD treatment shows protective effects against this pathology.

\section{CBD attenuates MA-induced myocardial necrosis in left ventricle}

To assess the extent of myocardial damage caused by MA exposure, we evaluated the left ventricle level of cTnl, an important biomarker of myocardial necrosis, via western blot analysis. As shown in Fig. 4C, MA significantly increased the expression of cTnl compared to that in the control group $(P<0.01)$, whereas pretreatment with $80 \mathrm{mg} / \mathrm{kg}$ CBD attenuated the level of cTnl compared to that in the MA group $(P<0.05)$, although no effect was observed under $40 \mathrm{mg} / \mathrm{kg}$ CBD.

\section{CBD down-regulates PKA, p-PKA, CREB, and p-CREB expression in left}

\section{ventricle following MA-inducedcardiotoxicity}

As shown in Fig. 5A and 5B, the expression levels of PKA $(P<0.01)$ and p-PKA $(P<0.05)$ were significantly higher in the MA group compared to the control group. However, pretreatment with $40 \mathrm{mg} / \mathrm{kg}$ or $80 \mathrm{mg} / \mathrm{kg}$ CBD reduced the expression levels of PKA and p-PKA compared to that in the MA group, with $80 \mathrm{mg} / \mathrm{kg}$ CBD more effective (PKA: $P<0.01$; p-PKA: $P<0.001$ ). As shown in Fig. $5 \mathrm{C}$ and 5D, the expression levels of CREB $(P<0.01)$ and p-CREB $(P<0.05)$ were significantly higher in the MA group compared to that in the control group. However, pretreatment with $40 \mathrm{mg} / \mathrm{kg}$ or $80 \mathrm{mg} / \mathrm{kg}$ CBD reduced the expression levels of CREB and p-CREB compared to that in the MA group. Interestingly, compared with $40 \mathrm{mg} / \mathrm{kg}$ CBD, $80 \mathrm{mg} / \mathrm{kg}$ CBD treatment did not significantly reduce the level of CREB, but was more effective for $\mathrm{p}$-CREB $(P<0.01)$.

\section{Discussion}

Previous studies have indicated that body mass index and heart weight are significantly higher in MA abusers than in non-MA users(Abdullah et al., 2020). In addition, compared with deaths caused by multiple drug toxicities, those from MA toxicity show heavier hearts(Darke et al., 2018). In the current 
study, we demonstrated that rat body weight increased significantly after 4 weeks of MA administration (Fig. 2A). These results are similar to previous findings showing an increasing trend in body weight in mice receiving MA (2 mg/kg, IP, 10 days), followed by withdrawal (7 days)(Garcia-Carmona et al., 2018), but differ from other research showing no significant differences in body weight in mice receiving MA (0$6 \mathrm{mg} / \mathrm{kg}$ ) via subcutaneous injection 5 days a week for 4 weeks(Abdullah et al., 2020). Heart weight was higher in the MA group than in the control group, but not significantly. Relative heart weight, calculated as the heart-to-body weight ratio, increased significantly in the MA group compared to the control group (Fig. 2C), consistent with that found in mice (i.e., increased $4-5 \mathrm{mg} /$ week for 8 weeks at $35 \mathrm{mg} / \mathrm{kg} \mathrm{MA}$ and $2 \mathrm{mg} /$ week after 20 weeks at $40 \mathrm{mg} / \mathrm{kg}$ )(Marcinko et al., 2019). In contrast, other research has reported no significant differences in relative heart weight in rats after an acute dose of $50 \mathrm{mg} / \mathrm{kg} \mathrm{MA}$ or in mice after 10 days of exposure to $2 \mathrm{mg} / \mathrm{kg} \mathrm{MA}$ (Islam et al., 2009, Garcia-Carmona et al., 2018). These discrepancies could be explained by the different concentrations and treatment times of MA administration, animal species tested, or specific experimental protocols used. The current study is also the first to report on the protective effects of $\mathrm{CBD}(80 \mathrm{mg} / \mathrm{kg})$ against MA-induced cardiomegaly in rats.

Various autopsy reports have revealed that cardiomyopathy, coronary artery stenosis, valvular heart disease, and inflammatory heart disease are involved in many MA-toxicity deaths, with myocyte hypertrophy, myocarditis, endocarditis, pericarditis, perivascular and interstitial fibrosis, fiber necrosis, collagen deposition, and subendocardial myocardial infarction found via microscopic examination(Nishida et al., 2003, Darke et al., 2017, Darke et al., 2018, Abdullah et al., 2020). The nonspecific cardiac histopathology observed in our study following MA exposure is similar with that reported in autopsy studies and animal models(Islam et al., 2009, Marcinko et al., 2019, Abdullah et al., 2020). Notably, inflammatory response, fibrosis, and necrosis of myocardial tissue were confirmed by H\&E staining, ELISA analysis, Masson's trichrome staining, and western blotting. Compared to the MA group, however, CBD pretreatment alleviated these lesions to a certain extent.

Long-term MA administration in $\mathrm{ApoE}^{-/-}$mice can lead to a significant increase in the levels of plasma Creactive protein, inflammatory cytokines (ICAM-1, VCAM-1, TNF- $a$ ), and neuropeptide $Y$ in the aortic root and myocardial tissue, which promote inflammation and atherosclerosis(Gao et al., 2015). Furthermore, acute exposure to MA in mice (30 mg/kg for $6 \mathrm{~h}$ ) results in a significant increase in serum IL-6, TNF-a, and IL-10, with a further increase under MA exposure and water-restraint stress(Tomita et al., 2011). Both the Nfkbiz gene (a regulator of NF-KB) and the Nr4a1 gene (a transcription factor) are up-regulated by NF$\mathrm{KB}$ signaling activation, which is associated with inflammatory response(Yamamoto et al., 2004, Shinone et al., 2010). Similarly, mRNA expression of Nfkbiz and Nr4a1 in the heart and TNF-a, IL-1 $\beta$, and IL-6 levels in serum are significantly induced in mice after MA exposure $(30 \mathrm{mg} / \mathrm{kg})$, with further increases in TNF-a and IL- 6 when the mice are restrained after MA administration(Shinone et al., 2010). These studies indicate that inflammation plays a key role in myocardial damage induced by MA, which can be aggravated by additional environmental stimuli. In the present study, IL-6 increased and IL-10 decreased after MA administration, but these changes were reversed by CBD ( 40 or $80 \mathrm{mg} / \mathrm{kg}$ ), suggesting that CBD may have an anti-inflammatory protective effect on myocardial damage induced by MA (Fig. 4A and 4B). 
Previous research has indicated that CBD treatment $(2 \mu \mathrm{g} / \mu \mathrm{l})$ can inhibit the increase in IL-1 $\beta$ mRNA expression in the prefrontal cortex of rats following MA exposure(Karimi-Haghighi et al., 2020). Furthermore, CBD treatment $(1.5 \mathrm{mg} / \mathrm{kg}, \mathrm{IP}, 10$ weeks) can significantly decrease pro-inflammatory cytokine IL-23, its receptor, CXCL-9, and CXCL-11 in mice with spinal cord injury, but not IL-6 or INF- $\mathrm{y}$ (Li et al., 2018). In rats with myocardial ischemic reperfusion injury, CBD (5 mg/kg, IP, 7 days) can reduce infract size, myocardial inflammation, and serum IL-6(Durst et al., 2007). Myocarditis, focal and diffuse myocardial fibrosis, and myocardial dysfunction are reported in patients with pheochromocytoma, indicating that catecholamine toxicity may lead to myocarditis and myocardial fibrosis(Ferreira et al., 2016). This is supported by our study, whereby MA induced a cardiac inflammatory response and myocardial fibrosis, but these effects were attenuated by CBD in a dose-dependent manner (Fig. 3 and Fig. 4). Thus, CBD exhibited considerable preventive and therapeutic effects against cardiac damage induced by MA exposure, which may be mediated by a reduced inflammatory response.

To evaluate the extent of myocardial necrosis caused by MA, we detected cTnl levels in the left ventricle using western blot analysis, as shown in Fig. 4C. Creatine kinase myocardial band (CK-MB) is a key biomarker of myocardial infarction. Autopsy studies have shown high cTnl expression in fatal MA abusers, with CK-MB levels also increased in cardiac and peripheral blood(Zhu et al., 2007) and pericardial and cerebrospinal fluids of MA abusers(Wang et al., 2011). Elevated levels of cTnI and CK-MB are indicative of increased myocardial necrosis, as found in our study following MA administration. However, we also found that CBD $(80 \mathrm{mg} / \mathrm{kg})$ pretreatment decreased cTnl levels compared to the MA group, indicating that high-dose CBD may have a protective effect on cardiac damage. Similar findings have been reported in rabbits with acute myocardial infraction, with CBD administration $(100 \mu \mathrm{g} / \mathrm{kg})$ significantly decreasing plasma levels of cTnl and reducing ischemic injury in the myocardium(Feng et al., 2015).

The distribution of MA in the major organs of MA-sensitized rats is reported to be higher in the brain and heart than in the kidney, blood, and abdominal muscle, and delayed efflux of MA in the heart may be associated with cardiac toxicity(Nakagawa et al., 2003). The brain corticotrophin releasing factor system, which is associated with cardiac sympathetic control, is activated by chronic MA administration and withdrawal in mice, which further activates the sympathetic pathways in the heart with increased levels of phospho-tyrosine hydroxylase ( $p-T H$ ) and p-heat shock protein 27 ( $p$-HSP 27), which may be the mechanism of cardiovascular risk related to MA abuse(Garcia-Carmona et al., 2018). Although various pathological mechanisms have been investigated, the mechanism underlying myocardial injury caused by MA remains unclear. Our data showed that the PKA/CREB signaling pathway was activated and $\mathrm{p}-\mathrm{PKA}$ and $p$-CREB increased in rats under chronic MA administration. These findings suggest that the PKA/CREB pathway participated in MA-induced myocardial inflammation and myocardial pathology. Increased cellular CAMP promotes the dissociation of PKA, the catalytic subunit of which migrates to the nucleus and phosphorylates CREB at a single phospho-acceptor site (ser 133), with p-CREB then promoting further transcription(Mayr and Montminy, 2001). PKA is the key kinase for CREB phosphorylation(Meyer et al., 2000), and CREB plays an important role in drug addiction(Zhou and Zhu, 2006). PKA, p-PKA, CREB, and p-CREB are highly expressed in different brain regions of MA-induced 
conditioned place preference (CPP) rats and in SH-SY5Y cells, but can be inhibited by gastrodin(Yang et al., 2020b). The cAMP/PKA/CREB pathway is also involved in the apoptosis of cortical neurons induced by MA, but can be regulated by the neuroprotective effects of gastrodin(Ma et al., 2020). In this study, the expression levels of PKA, p-PKA, CREB, and p-CREB decreased following CBD pretreatment, indicating that CBD may attenuate myocardial inflammation and cardiac pathology by mediating the PKA/CREB signaling pathway. Similarly, CBD has shown potential therapeutic effects on MA-induced CPP in rats via the PI3K/AKT/GSK-3ß/CREB signaling pathway(Yang et al., 2020a).

To the best of our knowledge, this study is the first to report on the protective effects of CBD on cardiac pathology elicited by chronic MA exposure in rats, with inhibition of cardiomegaly and reversal of histopathology, inflammatory response, and necrosis. Results showed that CBD at 40 and $80 \mathrm{mg} / \mathrm{kg}$ had a protective effect on MA-induced cardiac damage, although the effect was stronger at the higher concentration $(80 \mathrm{mg} / \mathrm{kg})$. These findings are similar with previous study showing that CBD at $80 \mathrm{mg} / \mathrm{kg}$, but not $40 \mathrm{mg} / \mathrm{kg}$, can reduce motivation of self-administered MA and drug-seeking behavior after extinction(Hay et al., 2018). CBD may exhibit cardioprotective effects by modulating the expression of crucial components of the CAMP/PKA/CREB signaling pathway. Our study highlights the potential clinical application of CBD in MA-induced cardiac pathology.

Our study demonstrated that chronic MA administration induced cardiomegaly and cardiac pathology in rats, with a notable increase in inflammatory response and myocardial necrosis. Interestingly, CBD pretreatment significantly and dose-dependently reduced the inflammatory response and myocardial necrosis via regulation of the PKA/CREB signaling pathway. These results indicate that CBD may have potential clinical application for the treatment of MA-induced cardiotoxicity. However, the specific molecular mechanism of MA-induced cardiotoxicity and the protective effects of CBD need to be further investigated.

\section{Declarations}

\section{Author Contributions}

The authors declare that all data were generated in-house and that no paper mill was used. S.H. and L.L. were responsible for overall direction of the project. Q.N. performed experiments and drafted the manuscript. W.D. and B.S. performed daily injections of methamphetamine and cannabidiol. G.Y. and H.Y. performed experiments. R.Z. and Y.P. collated data. Y.Y. performed data analysis. All authors read and approved the final manuscript.

\section{Funding information}

This work was supported by the National Natural Science Foundation of China (Grant No. 81760337 and 81860332), Research Project of the National Health Commission Key Laboratory of Drug Addiction Medicine, Kunming Medical University (Grant No. 2020DAMARC-002) and Scientific Research Foundation of Education Department of Yunnan Province (Grant No. 2021Y328). 
Availability of data and materials

Data and figures are available upon request.

\section{Competing Interests}

The authors have no relevant financial or non-financial interests to disclose.

\section{Ethics approval}

All animal studies were performed in accordance with the Guidelines for the Care and Use of Laboratory Animals of KMU, and all experimental procedures were approved by the Ethics Committee on Animal Care and Use from KMU (Approval code: kmmu2020403).

\section{Consent to Participate}

Not applicable.

\section{Consent to Publish}

Not applicable.

\section{References}

1. Abdullah CS, Aishwarya R, Alam S, Morshed M, Remex NS, Nitu S, Kolluru GK, Traylor J, Miriyala S, Panchatcharam M, Hartman B, King J, Bhuiyan MAN, Chandran S, Woolard MD, Yu X, Goeders NE, Dominic P, Arnold CL, Stokes K, Kevil CG, Orr AW, Bhuiyan MS (2020) Methamphetamine induces cardiomyopathy by Sigmar1 inhibition-dependent impairment of mitochondrial dynamics and function. Commun Biol 3: 682. https://doi.org/10.1038/s42003-020-01408-z

2. Akhgari M, Mobaraki $H$, Etemadi-Aleagha $A$ (2017) Histopathological study of cardiac lesions in methamphetamine poisoning-related deaths. Daru 25: 5. https://doi.org/10.1186/s40199-017-01704

3. Bergamaschi MM, Queiroz RH, Zuardi AW, Crippa JA (2011) Safety and side effects of cannabidiol, a Cannabis sativa constituent. Curr Drug Saf 6: 237-249. https://doi.org/10.2174/157488611798280924

4. Campos AC, Fogaca MV, Scarante FF, Joca SRL, Sales AJ, Gomes FV, Sonego AB, Rodrigues NS, Galve-Roperh I, Guimaraes FS (2017) Plastic and Neuroprotective Mechanisms Involved in the Therapeutic Effects of Cannabidiol in Psychiatric Disorders. Front Pharmacol 8: 269. https://doi.org/10.3389/fphar.2017.00269

5. Dalal S, Arustamyan M, Marmolejos G, Ramakrishna K (2020) Delayed cardiomyopathy and cardiogenic shock due to intravenous methamphetamine use requiring hemodynamic support with 
veno-arterial extracorporeal membrane oxygenation. J Am Coll Emerg Physicians Open 1: 117-119. https://doi.org/10.1002/emp2.12027

6. Darke S, Duflou J, Kaye S (2017) Prevalence and nature of cardiovascular disease in methamphetamine-related death: A national study. Drug Alcohol Depend 179: 174-179. https://doi.org/10.1016/j.drugalcdep.2017.07.001

7. Darke S, Duflou J, Lappin J, Kaye S (2018) Clinical and Autopsy Characteristics of Fatal Methamphetamine Toxicity in Australia. J Forensic Sci 63: 1466-1471. https://doi.org/10.1111/1556-4029.13710

8. Der-Ghazarian TS, Charmchi D, Noudali SN, Scott SN, Holter MC, Newbern JM, Neisewander JL (2019) Neural Circuits Associated with 5-HT1B Receptor Agonist Inhibition of Methamphetamine Seeking in the Conditioned Place Preference Model. ACS Chem Neurosci 10: 3271-3283. https://doi.org/10.1021/acschemneuro.8b00709

9. Devinsky O, Cilio MR, Cross H, Fernandez-Ruiz J, French J, Hill C, Katz R, Di Marzo V, Jutras-Aswad D, Notcutt WG, Martinez-Orgado J, Robson PJ, Rohrback BG, Thiele E, Whalley B, Friedman D (2014) Cannabidiol: pharmacology and potential therapeutic role in epilepsy and other neuropsychiatric disorders. Epilepsia 55: 791-802. https://doi.org/10.1111/epi.12631

10. Durst R, Danenberg H, Gallily R, Mechoulam R, Meir K, Grad E, Beeri R, Pugatsch T, Tarsish E, Lotan C (2007) Cannabidiol, a nonpsychoactive Cannabis constituent, protects against myocardial ischemic reperfusion injury. American journal of physiology Heart and circulatory physiology 293: H36023607. https://doi.org/10.1152/ajpheart.00098.2007

11. Feng Y, Chen F, Yin T, Xia Q, Liu Y, Huang G, Zhang J, Oyen R, Ni Y (2015) Pharmacologic Effects of Cannabidiol on Acute Reperfused Myocardial Infarction in Rabbits: Evaluated With 3.0T Cardiac Magnetic Resonance Imaging and Histopathology. J Cardiovasc Pharmacol 66: 354-363. https://doi.org/10.1097/fjc.0000000000000287

12. Ferreira VM, Marcelino M, Piechnik SK, Marini C, Karamitsos TD, Ntusi NAB, Francis JM, Robson MD, Arnold JR, Mihai R, Thomas JDJ, Herincs M, Hassan-Smith ZK, Greiser A, Arlt W, Korbonits M, Karavitaki N, Grossman AB, Wass JAH, Neubauer S (2016) Pheochromocytoma Is Characterized by Catecholamine-Mediated Myocarditis, Focal and Diffuse Myocardial Fibrosis, and Myocardial Dysfunction. J Am Coll Cardiol 67: 2364-2374. https://doi.org/10.1016/j.jacc.2016.03.543

13. Friend DM, Son JH, Keefe KA, Fricks-Gleason AN (2013) Expression and activity of nitric oxide synthase isoforms in methamphetamine-induced striatal dopamine toxicity. J Pharmacol Exp Ther 344: 511-521. https://doi.org/10.1124/jpet.112.199745

14. Gao B, Li L, Zhu P, Zhang M, Hou L, Sun Y, Liu X, Peng X, Gu Y (2015) Chronic administration of methamphetamine promotes atherosclerosis formation in ApoE-/- knockout mice fed normal diet. Atherosclerosis 243: 268-277. https://doi.org/10.1016/j.atherosclerosis.2015.09.001

15. Garcia-Arencibia M, Gonzalez S, de Lago E, Ramos JA, Mechoulam R, Fernandez-Ruiz J (2007) Evaluation of the neuroprotective effect of cannabinoids in a rat model of Parkinson's disease: 
importance of antioxidant and cannabinoid receptor-independent properties. Brain Res 1134: 162170. https://doi.org/10.1016/j.brainres.2006.11.063

16. Garcia-Carmona JA, Georgiou P, Zanos P, Bailey A, Laorden ML (2018) Methamphetamine withdrawal induces activation of CRF neurons in the brain stress system in parallel with an increased activity of cardiac sympathetic pathways. Naunyn Schmiedebergs Arch Pharmacol 391: 423-434. https://doi.org/10.1007/s00210-018-1470-z

17. Gurel A (2016) Multisystem toxicity after methamphetamine use. Clin Case Rep 4: 226-227. https://doi.org/10.1002/ccr3.487

18. Han DD, Gu HH (2006) Comparison of the monoamine transporters from human and mouse in their sensitivities to psychostimulant drugs. BMC Pharmacol 6: 6. https://doi.org/10.1186/1471-2210-6-6

19. Hay GL, Baracz SJ, Everett NA, Roberts J, Costa PA, Arnold JC, McGregor IS, Cornish JL (2018) Cannabidiol treatment reduces the motivation to self-administer methamphetamine and methamphetamine-primed relapse in rats. J Psychopharmacol 32: 1369-1378. https://doi.org/10.1177/0269881118799954

20. Hendrickson K, Strauss W (2020) Characterization and treatment challenges of pulmonary hypertension in methamphetamine users. Respir Med Case Rep 31: 101275. https://doi.org/10.1016/j.rmcr.2020.101275

21. Homer BD, Solomon TM, Moeller RW, Mascia A, DeRaleau L, Halkitis PN (2008) Methamphetamine abuse and impairment of social functioning: a review of the underlying neurophysiological causes and behavioral implications. Psychol Bull 134: 301-310.

22. Islam MN, Khan J, Jaafar H (2009) Leave methamphetamine to be alive--Part II. Leg Med (Tokyo) 11 Suppl 1: S143-146. https://doi.org/10.1016/j.legalmed.2009.02.045

23. Isoardi KZ, Mudge DW, Harris K, Dimeski G, Buckley NA (2020) Methamphetamine intoxication and acute kidney injury: A prospective observational case series. Nephrology (Carlton) 25: 758-764. https://doi.org/10.1111/nep.13762

24. Karimi-Haghighi S, Dargahi L, Haghparast A (2020) Cannabidiol modulates the expression of neuroinflammatory factors in stress- and drug-induced reinstatement of methamphetamine in extinguished rats. Addict Biol 25: e12740. https://doi.org/10.1111/adb.12740

25. Kevil CG, Goeders NE, Woolard MD, Bhuiyan MS, Dominic P, Kolluru GK, Arnold CL, Traylor JG, Orr AW (2019) Methamphetamine Use and Cardiovascular Disease. Arterioscler Thromb Vasc Biol 39: 17391746. https://doi.org/10.1161/atvbaha.119.312461

26. Kohno M, Beste C, Pilhatsch M (2020) Editorial: The Global Methamphetamine Problem: Approaches to Elucidate the Neurobiology, Epidemiology, and Therapeutic Effectiveness. Frontiers in psychiatry 11: 850. https://doi.org/10.3389/fpsyt.2020.00850

27. Krasnova IN, Cadet JL (2009) Methamphetamine toxicity and messengers of death. Brain Res Rev 60: 379-407. https://doi.org/10.1016/j.brainresrev.2009.03.002

28. Lewin AH, Miller GM, Gilmour B (2011) Trace amine-associated receptor 1 is a stereoselective binding site for compounds in the amphetamine class. Bioorg Med Chem 19: 7044-7048. 
https://doi.org/10.1016/j.bmc.2011.10.007

29. Li H, Kong W, Chambers CR, Yu D, Ganea D, Tuma RF, Ward SJ (2018) The non-psychoactive phytocannabinoid cannabidiol (CBD) attenuates pro-inflammatory mediators, $\mathrm{T}$ cell infiltration, and thermal sensitivity following spinal cord injury in mice. Cell Immunol 329: 1-9. https://doi.org/10.1016/j.cellimm.2018.02.016

30. Li QQ, Shi GX, Yang JW, Li ZX, Zhang ZH, He T, Wang J, Liu LY, Liu CZ (2015) Hippocampal CAMP/PKA/CREB is required for neuroprotective effect of acupuncture. Physiol Behav 139: 482-490. https://doi.org/10.1016/j.physbeh.2014.12.001

31. Liang R, Zhou Y, Wu F, Zhou C, Zhao X, Zhang M, Tian X, Zhu B (2010) Effect of methamphetamine on potassium and L-type calcium currents in rat ventricular myocytes. Toxicol Mech Methods 20: 458-465. https://doi.org/10.3109/15376516.2010.497979

32. Lord KC, Shenouda SK, Mcllwain E, Charalampidis D, Lucchesi PA, Varner KJ (2010) Oxidative stress contributes to methamphetamine-induced left ventricular dysfunction. Cardiovasc Res 87: 111-118. https://doi.org/10.1093/cvr/cvq043

33. Ma CL, Li L, Yang GM, Zhang ZB, Zhao YN, Zeng XF, Zhang DX, Yu Y, Shi ZJ, Yan QW, Li LH, Hong SJ (2020) Neuroprotective effect of gastrodin in methamphetamine-induced apoptosis through regulating cAMP/PKA/CREB pathway in cortical neuron. Hum Exp Toxicol 39: 1118-1129. https://doi.org/10.1177/0960327120911438

34. Marcinko MC, Darrow AL, Tuia AJ, Shohet RV (2019) Sex influences susceptibility to methamphetamine cardiomyopathy in mice. Physiol Rep 7: e14036. https://doi.org/10.14814/phy2.14036

35. Mayr B, Montminy M (2001) Transcriptional regulation by the phosphorylation-dependent factor CREB. Nat Rev Mol Cell Biol 2: 599-609. https://doi.org/10.1038/35085068

36. Mechoulam R, Hanus L (2002) Cannabidiol: an overview of some chemical and pharmacological aspects. Part I: chemical aspects. Chem Phys Lipids 121: 35-43. https://doi.org/10.1016/s00093084(02)00144-5

37. Meng X, Zhang C, Guo Y, Han Y, Wang C, Chu H, Kong L, Ma H (2020) TBHQ Attenuates Neurotoxicity Induced by Methamphetamine in the VTA through the Nrf2/HO-1 and PI3K/AKT Signaling Pathways. Oxid Med Cell Longev 2020: 8787156. https://doi.org/10.1155/2020/8787156

38. Meyer CJ, Alenghat FJ, Rim P, Fong JH, Fabry B, Ingber DE (2000) Mechanical control of cyclic AMP signaling and gene transcription through integrins. Nat Cell Biol 2: 666-668.

https://doi.org/10.1038/35023621

39. Moratalla R, Khairnar A, Simola N, Granado N, Garcia-Montes JR, Porceddu PF, Tizabi Y, Costa G, Morelli M (2017) Amphetamine-related drugs neurotoxicity in humans and in experimental animals: Main mechanisms. Prog Neurobiol 155: 149-170. https://doi.org/10.1016/j.pneurobio.2015.09.011

40. Nakagawa N, Hishinuma T, Nakamura H, Yamazaki T, Tsukamoto H, Hiratsuka M, Ido T, Mizugaki M, Terasaki T, Goto J (2003) Brain and heart specific alteration of methamphetamine (MAP) distribution in MAP-sensitized rat. Biol Pharm Bull 26: 506-509. https://doi.org/10.1248/bpb.26.506 
41. Nguyen EC, McCracken KA, Liu Y, Pouw B, Matsumoto RR (2005) Involvement of sigma (sigma) receptors in the acute actions of methamphetamine: receptor binding and behavioral studies. Neuropharmacology 49: 638-645. https://doi.org/10.1016/j.neuropharm.2005.04.016

42. Nichols JM, Kaplan BLF (2020) Immune Responses Regulated by Cannabidiol. Cannabis Cannabinoid Res 5: 12-31. https://doi.org/10.1089/can.2018.0073

43. Nishida N, Ikeda N, Kudo K, Esaki R (2003) Sudden unexpected death of a methamphetamine abuser with cardiopulmonary abnormalities: a case report. Med Sci Law 43: 267-271. https://doi.org/10.1258/rsmmsl.43.3.267

44. Nishimura M, Ma J, Fox S, Toomu A, Mojaver S, Juang DK, Maisel AS, Thomas IC (2019) Characteristics and Outcomes of Methamphetamine Abuse Among Veterans With Heart Failure. Am J Cardiol 124: 907-911. https://doi.org/10.1016/j.amjcard.2019.05.068

45. Pan AL, Hasalliu E, Hasalliu M, Angulo JA (2020) Epigallocatechin Gallate Mitigates the Methamphetamine-Induced Striatal Dopamine Terminal Toxicity by Preventing Oxidative Stress in the Mouse Brain. Neurotox Res 37: 883-892. https://doi.org/10.1007/s12640-020-00177-1

46. Paratz ED, Cunningham NJ, Maclsaac Al (2016) The Cardiac Complications of Methamphetamines. Heart Lung Circ 25: 325-332. https://doi.org/10.1016/j.hlc.2015.10.019

47. Potula R, Hawkins BJ, Cenna JM, Fan S, Dykstra H, Ramirez SH, Morsey B, Brodie MR, Persidsky Y (2010) Methamphetamine causes mitrochondrial oxidative damage in human T lymphocytes leading to functional impairment. J Immunol 185: 2867-2876. https://doi.org/10.4049/jimmunol.0903691

48. Razavi Y, Shabani R, Mehdizadeh M, Haghparast A (2020) Neuroprotective effect of chronic administration of cannabidiol during the abstinence period on methamphetamine-induced impairment of recognition memory in the rats. Behav Pharmacol 31: 385-396. https://doi.org/10.1097/fbp.0000000000000544

49. Reddy PKV, Ng TMH, Oh EE, Moady G, Elkayam U (2020) Clinical Characteristics and Management of Methamphetamine-Associated Cardiomyopathy: State-of-the-Art Review. J Am Heart Assoc 9: e016704. https://doi.org/10.1161/JAHA.120.016704

50. Reiner BC, Keblesh JP, Xiong H (2009) Methamphetamine abuse, HIV infection, and neurotoxicity. Int J Physiol Pathophysiol Pharmacol 1: 162-179.

51. Rusyniak DE (2011) Neurologic manifestations of chronic methamphetamine abuse. Neurol Clin $29:$ 641-655. https://doi.org/10.1016/j.psc.2013.02.005

52. Sands TT, Rahdari S, Oldham MS, Caminha Nunes E, Tilton N, Cilio MR (2019) Long-Term Safety, Tolerability, and Efficacy of Cannabidiol in Children with Refractory Epilepsy: Results from an Expanded Access Program in the US. CNS Drugs 33: 47-60. https://doi.org/10.1007/s40263-0180589-2

53. Schurer S, Klingel K, Sandri M, Majunke N, Besler C, Kandolf R, Lurz P, Luck M, Hertel P, Schuler G, Linke A, Mangner N (2017) Clinical Characteristics, Histopathological Features, and Clinical Outcome 
of Methamphetamine-Associated Cardiomyopathy. JACC Heart Fail 5: 435-445. https://doi.org/10.1016/j.jchf.2017.02.017

54. Segawa T, Arita Y, Ogasawara N, Hasegawa S (2019) Hypertensive heart disease associated with methamphetamine abuse. J Cardiol Cases 19: 47-50. https://doi.org/10.1016/j.jccase.2018.10.001

55. Sethwala AM, Goh I, Amerena JV (2021) Combating Inflammation in Cardiovascular Disease. Heart Lung Circ 30: 197-206. https://doi.org/10.1016/j.hlc.2020.09.003

56. Shaerzadeh F, Streit WJ, Heysieattalab S, Khoshbouei H (2018) Methamphetamine neurotoxicity, microglia, and neuroinflammation. J Neuroinflammation 15: 341. https://doi.org/10.1186/s12974018-1385-0

57. Shayesteh MRH, Haghi-Aminjan H, Mousavi MJ, Momtaz S, Abdollahi M (2019) The Protective Mechanism of Cannabidiol in Cardiac Injury: A Systematic Review of Non-Clinical Studies. Current Pharmaceutical Design 25: 2499-2507. https://doi.org/10.2174/2210327909666190710103103

58. Shinone K, Tomita M, Inoue H, Nakagawa Y, Ikemura M, Nata M (2010) Molecular-biological analysis of the effect of methamphetamine on the heart in restrained mice. Leg Med (Tokyo) 12: 79-83. https://doi.org/10.1016/j.legalmed.2010.01.001

59. Song Z, Zou S, Zhou W, Huang Y, Shao L, Yuan J, Gou X, Jin W, Wang Z, Chen X, Ding X, Liu J, Yu C, Ku C, Liu C, Sun Z, Xu G, Wang Y, Zhang X, Wang D, Wang S, Xu W, Davis RC, Shi H (2020) Clinically applicable histopathological diagnosis system for gastric cancer detection using deep learning. Nature Communications 11. https://doi.org/10.1038/s41467-020-18147-8

60. Spivak B, Shepherd S, Borschmann R, Kinner SA, Ogloff JRP, Hachtel H (2020) Crystalline methamphetamine (ice) use prior to youth detention: A forensic concern or a public health issue? PloS one 15: e0229389. https://doi.org/10.1371/journal.pone.0229389

61. Sulzer D, Sonders MS, Poulsen NW, Galli A (2005) Mechanisms of neurotransmitter release by amphetamines: a review. Prog Neurobiol 75: 406-433. https://doi.org/10.1016/j.pneurobio.2005.04.003

62. Sunda F, Arowolo A (2020) A molecular basis for the anti-inflammatory and anti-fibrosis properties of cannabidiol. FASEB J 34: 14083-14092. https://doi.org/10.1096/fj.202000975r

63. Tanaka S, Imaeda A, Matsumoto K, Maeda M, Obana M, Fujio Y (2020) beta2-adrenergic stimulation induces interleukin- 6 by increasing Arid5a, a stabilizer of mRNA, through cAMP/PKA/CREB pathway in cardiac fibroblasts. Pharmacol Res Perspect 8: e00590. https://doi.org/10.1002/prp2.590

64. Tomita M, Katsuyama H, Watanabe Y, Hidaka K, Yoshitome K, Miyaishi S, Ishikawa T, Shinone K, Nata M (2011) Water-restraint stress enhances methamphetamine-induced cardiotoxicity. ChemicoBiological Interactions 190: 54-61. https://doi.org/10.1016/j.cbi.2011.01.025

65. Vandesquille M, Baudonnat M, Decorte L, Louis C, Lestage P, Beracochea D (2013) Working memory deficits and related disinhibition of the CAMP/PKA/CREB are alleviated by prefrontal alpha4beta2*nAChRs stimulation in aged mice. Neurobiol Aging 34: 1599-1609.

https://doi.org/10.1016/j.neurobiolaging.2012.10.006 
66. Wan F, Zang S, Yu G, Xiao H, Wang J, Tang J (2017) Ginkgolide B Suppresses MethamphetamineInduced Microglial Activation Through TLR4-NF-kappaB Signaling Pathway in BV2 Cells. Neurochem Res 42: 2881-2891. https://doi.org/10.1007/s11064-017-2309-6

67. Wang Q, Dai X, Yang W, Wang H, Zhao H, Yang F, Yang Y, Li J, Lv X (2015) Caffeine protects against alcohol-induced liver fibrosis by dampening the CAMP/PKA/CREB pathway in rat hepatic stellate cells. Int Immunopharmacol 25: 340-352. https://doi.org/10.1016/j.intimp.2015.02.012

68. Wang Q, Michiue T, Ishikawa T, Zhu BL, Maeda H (2011) Combined analyses of creatine kinase MB, cardiac troponin I and myoglobin in pericardial and cerebrospinal fluids to investigate myocardial and skeletal muscle injury in medicolegal autopsy cases. Leg Med (Tokyo) 13: 226-232. https://doi.org/10.1016/j.legalmed.2011.05.002

69. Won S, Hong RA, Shohet RV, Seto TB, Parikh NI (2013) Methamphetamine-associated cardiomyopathy. Clin Cardiol 36: 737-742. https://doi.org/10.1002/clc.22195

70. World Drug Report 2020 (United Nations publication, Sales No. E.20.XI.6).

71. www.unodc.org/wdr2020

72. Wu XL, Li X, Li Y, Kong LP, Fang JL, Zhou XS, Li M, Jia JJ, Bai J (2016) The overexpression of Thioredoxin-1 suppressing inflammation induced by methamphetamine in spleen. Drug Alcohol Depend 159: 66-71. https://doi.org/10.1016/j.drugalcdep.2015.11.021

73. Yamamoto M, Yamazaki S, Uematsu S, Sato S, Hemmi H, Hoshino K, Kaisho T, Kuwata H, Takeuchi O, Takeshige K, Saitoh T, Yamaoka S, Yamamoto N, Yamamoto S, Muta T, Takeda K, Akira S (2004) Regulation of Toll/IL-1-receptor-mediated gene expression by the inducible nuclear protein IkappaBzet a. Nature 430: 218-222. https://doi.org/10.1038/nature02738

74. Yang G, Liu L, Zhang R, Li J, Leung CK, Huang J, Li Y, Shen B, Zeng X, Zhang D (2020a) Cannabidiol attenuates methamphetamine-induced conditioned place preference via the Sigma1R/AKT/GSK3beta/CREB signaling pathway in rats. Toxicol Res (Camb) 9: 202-211. https://doi.org/10.1093/toxres/tfaa021

75. Yang GM, Li L, Xue FL, Ma CL, Zeng XF, Zhao YN, Zhang DX, Yu Y, Yan QW, Zhou YQ, Hong SJ, Li LH (2020b) The Potential Role of PKA/CREB Signaling Pathway Concerned with Gastrodin Administration on Methamphetamine-Induced Conditioned Place Preference Rats and SH-SY5Y Cell Line. Neurotox Res 37: 926-935. https://doi.org/10.1007/s12640-019-00150-7

76. Zhou LF, Zhu YP (2006) Changes of CREB in rat hippocampus, prefrontal cortex and nucleus accumbens during three phases of morphine induced conditioned place preference in rats. $\mathrm{J}$ Zhejiang Univ Sci B 7: 107-113. https://doi.org/10.1631/jzus.2006.b0107

77. Zhu BL, Ishikawa T, Michiue T, Li DR, Zhao D, Bessho Y, Kamikodai Y, Tsuda K, Okazaki S, Maeda H (2007) Postmortem cardiac troponin I and creatine kinase MB levels in the blood and pericardial fluid as markers of myocardial damage in medicolegal autopsy. Leg Med (Tokyo) 9: 241-250. https://doi.org/10.1016/j.legalmed.2007.01.010

\section{Figures}




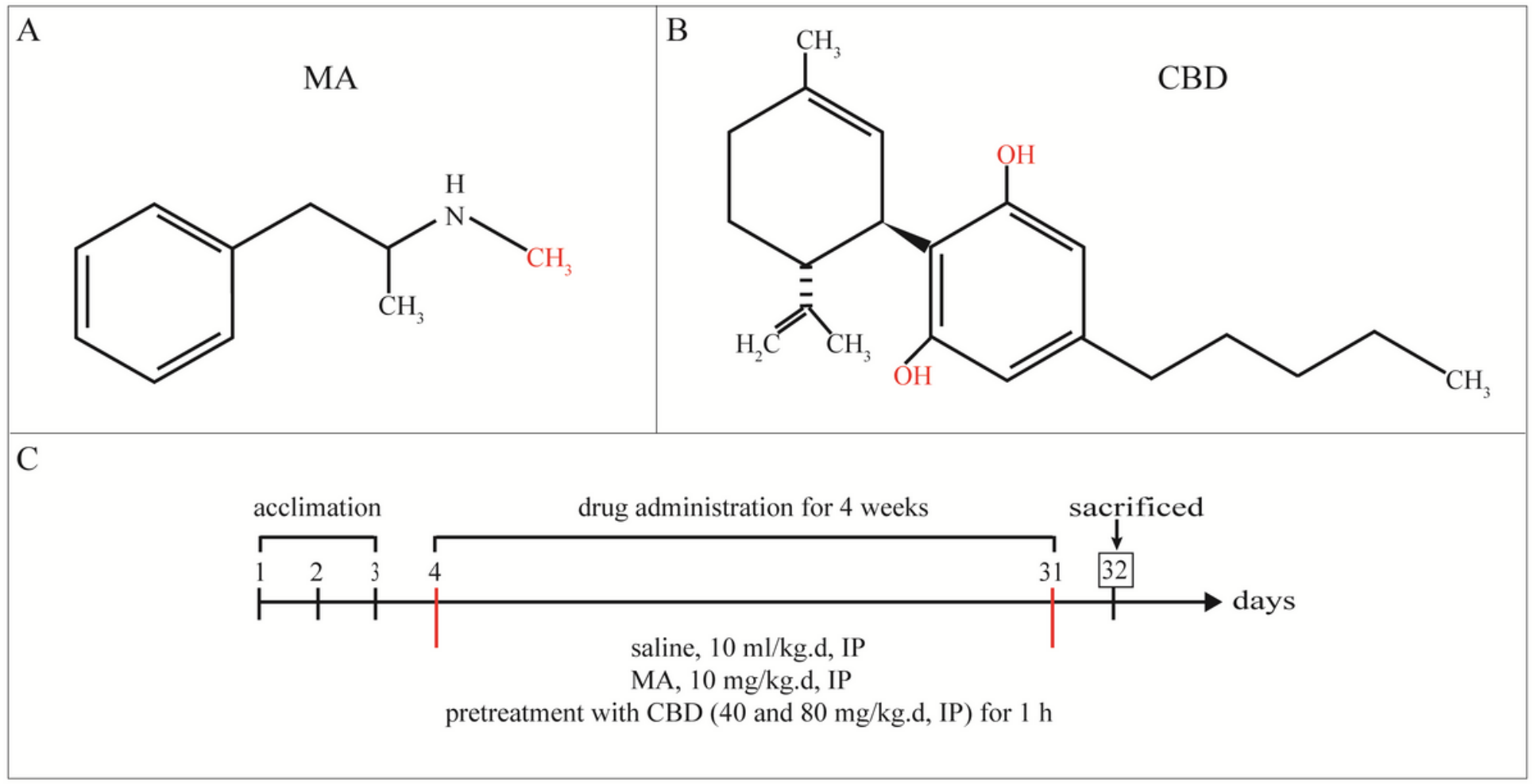

Figure 1

Experimental design for CBD and MA treatments in rats. (A) Chemical structure of MA. (B) Chemical structure of CBD. (C) Acclimation phase (days 1-3). Drug administration was once a day over 4 weeks (days 4-31). Rats in MA group received MA (10 mg/kg) by intraperitoneal injection (IP). $C B_{40}+M A$ group and $\mathrm{CBD}_{80}+\mathrm{MA}$ group rats received $\mathrm{MA}(10 \mathrm{mg} / \mathrm{kg})$ following 1-h CBD treatment (40 or $80 \mathrm{mg} / \mathrm{kg}$, IP). Control group rats received saline solution (containing 5\% DMSO + 5\% Tween-80, $10 \mathrm{ml} / \mathrm{kg}, \mathrm{IP}$ ). Rats in $\mathrm{CBD}_{80}$ group received CBD only $(80 \mathrm{mg} / \mathrm{kg}, \mathrm{IP})$. On day 32 , all rats were sacrificed for collection of hearts and cardiac blood for further analysis.
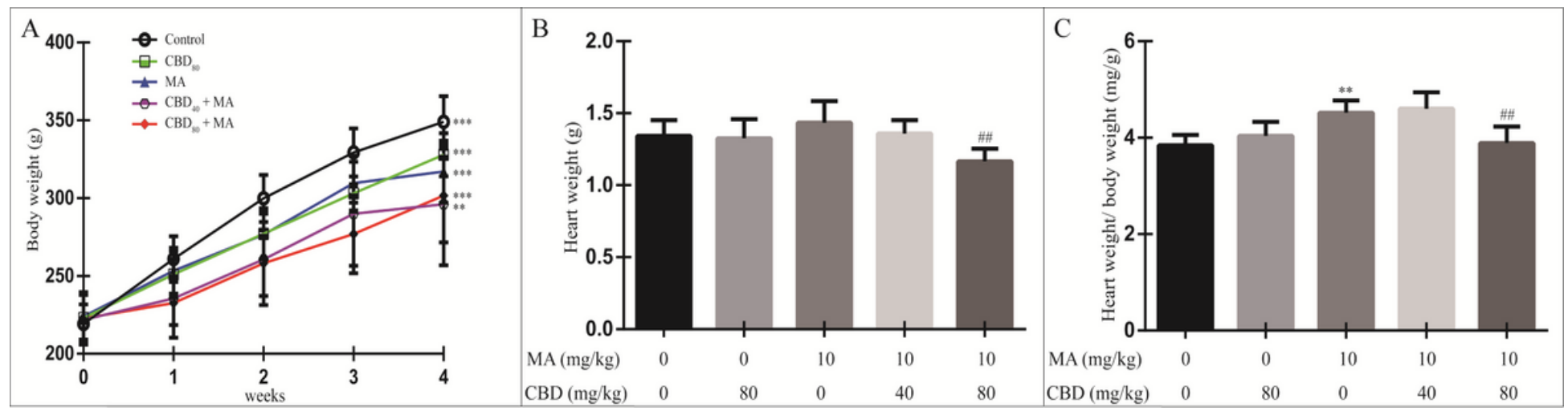

Figure 2

Effects of CBD on MA-induced body and heart weight changes in rats. Rats were pretreated with CBD (40 or $80 \mathrm{mg} / \mathrm{kg}, \mathrm{IP})$ for $1 \mathrm{~h}$ before administration of MA (10 mg/kg, IP), once a day for 4 weeks. (A) Effects 
of CBD on MA-induced body weight changes. Data are mean $\pm \mathrm{SD}$, and paired $t$ tests were applied to evaluate body weight, ${ }^{* *} P<0.01,{ }^{* * *} P<0.001$ vs. before drug administration ( 0 week). (B) Effects of CBD on MA-induced heart weight gain. Data are mean $\pm S D,{ }^{\# \#} P<0.01$ vs. MA group. (C) Effects of CBD on MA-induced heart-to-body weight ratio increase. Data are mean $\pm \mathrm{SD}, * * P<0.01$ vs. control group; ${ }^{\# \# ~} P$ $<0.01$ vs. MA group.

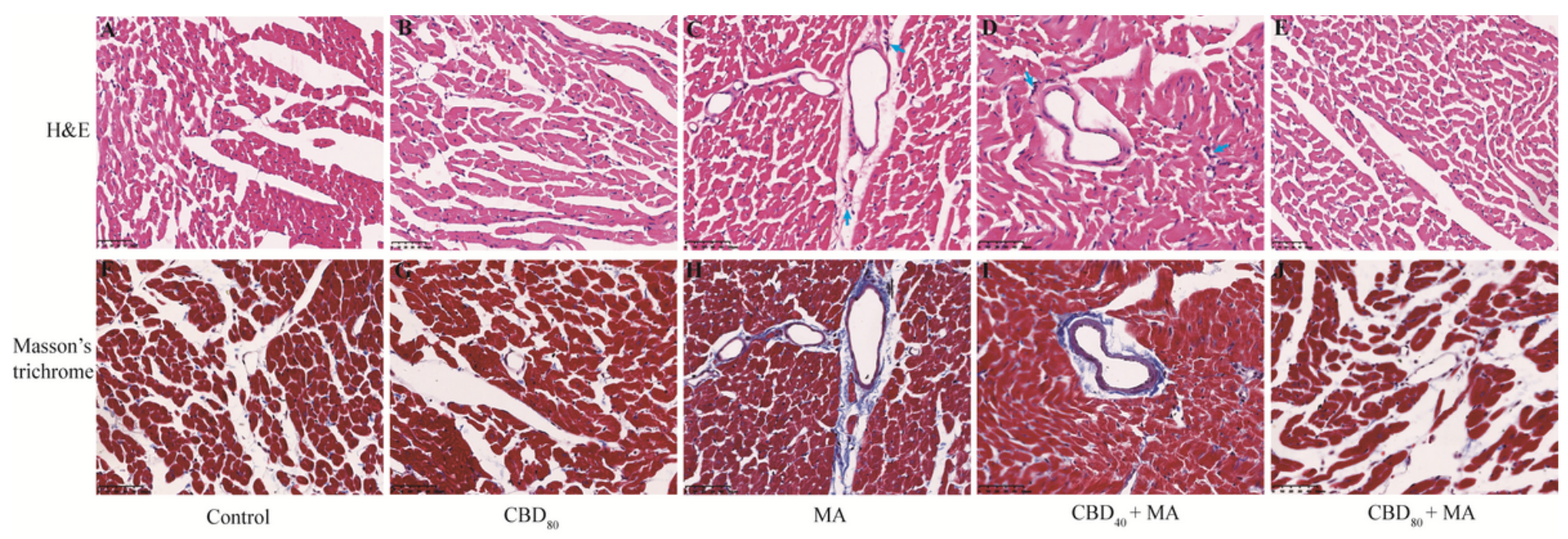

\section{Figure 3}

Effects of CBD on MA-induced cardiac histopathological changes. Rats were pretreated with CBD (40 or $80 \mathrm{mg} / \mathrm{kg}$, IP) for $1 \mathrm{~h}$ before administration of MA (10 mg/kg, IP), once a day for 4 weeks. Images represent hematoxylin \& eosin (H\&E) and Masson's trichrome staining, respectively. Scale bar, $50 \mu \mathrm{m}$. (A) Control and (B) $\mathrm{CBD}_{80}$ groups showed normal myocardial tissue structure. (C) MA group showed myocardial fiber disorder, myocyte vacuolization, and mononuclear inflammatory infiltration with myocardial fibrosis or necrosis (blue arrow). (D) $\mathrm{CBD}_{40}+\mathrm{MA}$ group showed less myocardial injury than MA group, but still exhibited mononuclear inflammatory infiltration with fibrosis or necrosis in interstitial spaces or around blood vessels (blue arrow). (E) $\mathrm{CBD}_{80}+\mathrm{MA}$ group showed cardiac myocyte degeneration. Compared with $(F)$ control group and $(G) C B D_{80}$ group, $(H)$ MA group showed blue-stained collagen fibrils in perivascular and interstitial spaces. (I) $\mathrm{CBD}_{40}+\mathrm{MA}$ group showed less perivascular and interstitial fibrosis compared with MA group. $(J) C B D_{80}+M A$ group showed almost no collagen fibrils in perivascular and interstitial spaces. 


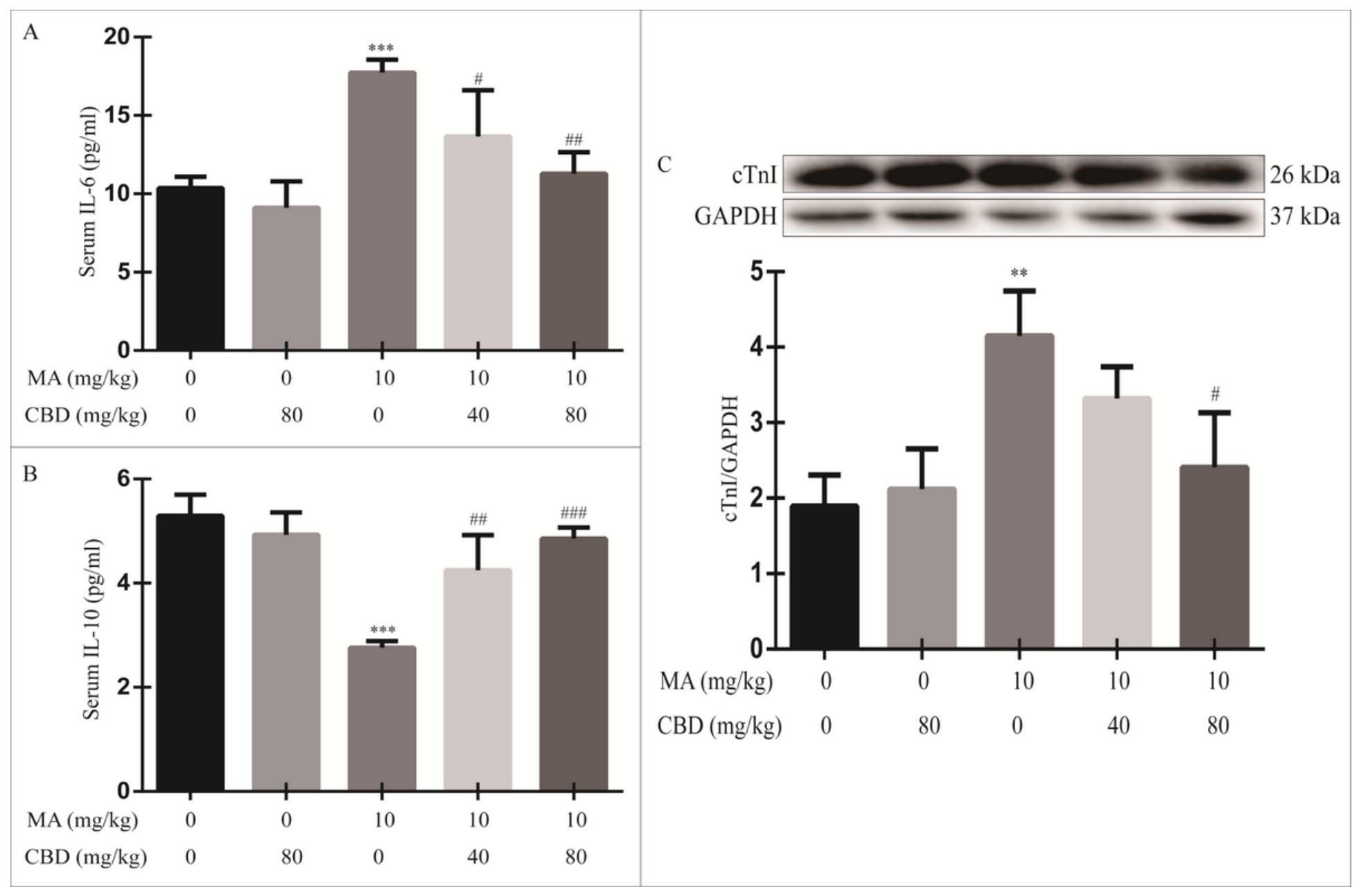

Figure 4

Effects of CBD on MA-induced cytokine and cTnl expression. Rats were pretreated with CBD (40 or 80 $\mathrm{mg} / \mathrm{kg}, \mathrm{IP})$ for $1 \mathrm{~h}$ before administration of MA $(10 \mathrm{mg} / \mathrm{kg}$, IP), once a day for 4 weeks. Serum levels of IL6 (A) and IL-10 (B) were detected by ELISA. (C) CTnI expression in left ventricle was measured by western blot analysis. Data are mean $\pm \mathrm{SD},{ }^{* *} P<0.01,{ }^{* * *} P<0.001$ vs. control group; ${ }^{\#} P<0.005,{ }^{\# \#} P<0.01,{ }^{\# \#} P$ $<0.001$ vs. MA group. 


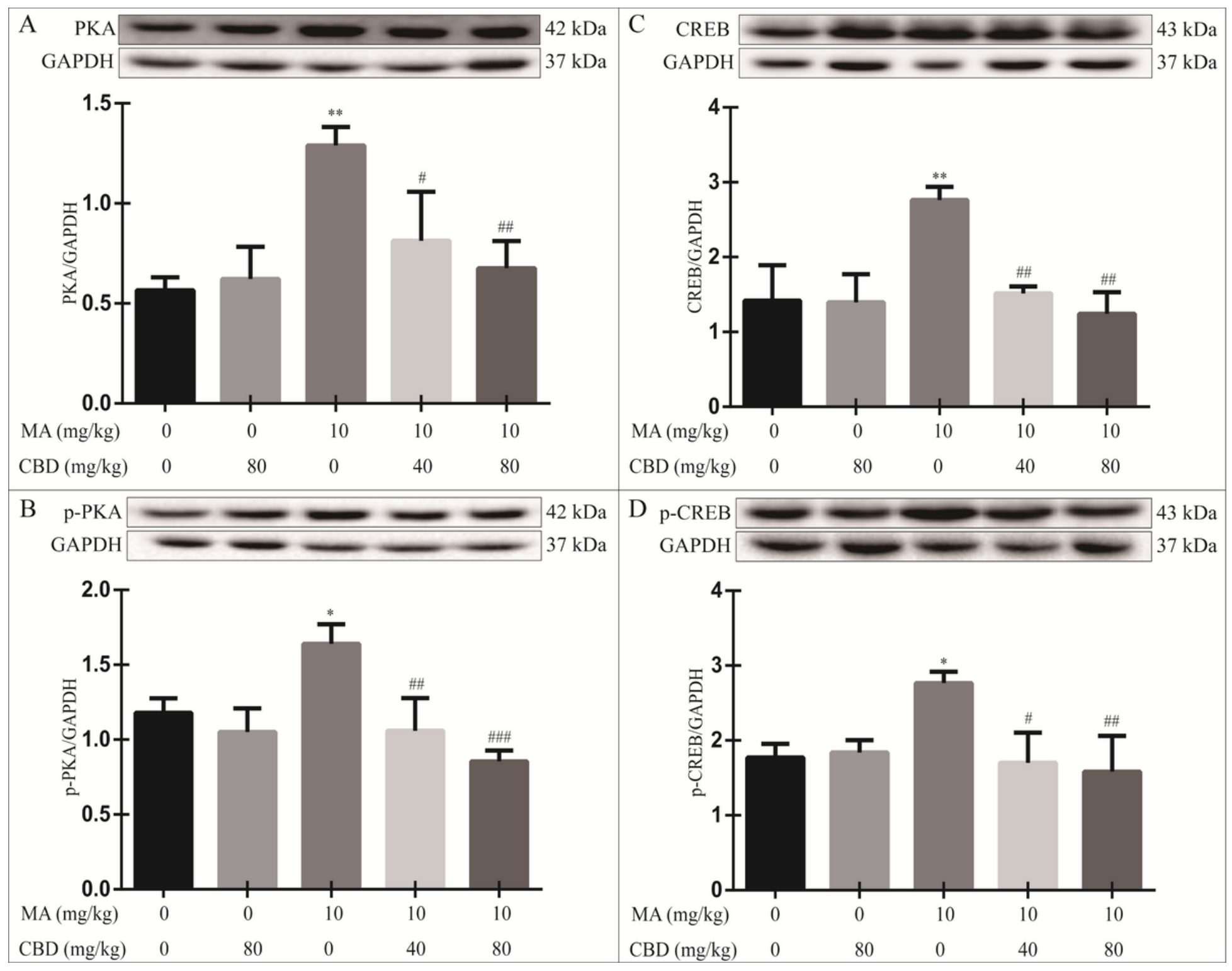

Figure 5

Effects of CBD on PKA, p-PKA, CREB, and p-CREB in left ventricle of MA-induced rats. Rats were pretreated with CBD (40 or $80 \mathrm{mg} / \mathrm{kg}$, IP) for $1 \mathrm{~h}$ before administration of MA (10 mg/kg, IP), once a day for 4 weeks. Expression levels of PKA (A), p-PKA (B), CREB (C), and p-CREB (D) were measured by western blot analysis. Data are mean $\pm \mathrm{SD},{ }^{*} P<0.05,{ }^{* *} P<0.01$ vs. control group; ${ }^{\#} P<0.005,{ }^{\# \#} P<0.01,{ }^{\# \#} P<$ 0.001 vs. MA group.

\section{Supplementary Files}

This is a list of supplementary files associated with this preprint. Click to download.

- originalsourcedata.pdf 